\title{
Information and Communication Technology Education Based on the Russian State Educational Standard of "Applied Mathematics and Informatics"
}

\author{
Iurii A. Bogoiavlenskii \\ Petrozavodsk State University, Petrozavodsk, Republic of Karelia, 185910, Russia \\ ybgvacs. karelia.ru
}

We strive in life so in the end Paradise attain, to heavens ascend. It is better our ways amend This moment now, joyously spend.

- Rubaiyat of Omar Khayyam English translation by Shahriar Shahriari

\begin{abstract}
The expansion of the computing field seriously challenges academic planning, as it requires acceleration of new curricula development and implementation. Academia possesses much inertia and curricula changes are slower than the computing expansion. American computer societies under the aegis of ACM and IEEE have developed separate curricular guidelines for disciplines in computer engineering, computer science, information systems, information technology, and software engineering. Our analysis of the guidelines shows that they contain a large amount of mathematical courses. We offer a "reverse" approach to curricular guidelines development where we introduce engineering components in the existing curriculum with intensified mathematical training. In the Russian Federation, we may use the "Applied Mathematics and Informatics" standard for these purposes. Our comparative analysis of body of knowledge cores for four disciplines (except computer engineering) shows that these core areas are entirely accommodated in the core of the Russian standard. We believe that mathematical culture provides longterm efficient professional activity of graduates.
\end{abstract}

Keywords: Computing curricula, Intensified mathematical training, body of knowledge cores, Russian standard.

\section{Introduction}

In this article, we will use the term "information and communication technologies" (ICT) as an analogue to the term "computing" as accepted in the United States. The ICT field is rapidly expanding; governments and private companies invest in its development vast sums of money. New paradigms, concepts, standards, tools, and application systems appear and deployed very quickly, supplementing and/or replacing each other. 
Considering this process, the authors of [1] note that the 1990s witnessed ICT specialist diversification, which resulted in the formation of five family disciplines: computer engineering (CE) [2], computer science (CS) [3], information systems (IS) [4], information technology (IT) [5], and software engineering (SE) [6]. This development considerably increases both importance and complexity of adequate curricula models development and deployment problems to accomplish the task of grounding specialists capable of long-term efficient professional activity in ICT fields. This problem is constantly the focus of attention for ICT communities in the United States [1-7], in Russia [8-14], and worldwide [15] as well.

In [1] the committee proposed to have separate curricular guidelines of undergraduate programs for each of the five disciplines. The purpose of this article is to show that it is possible (and expedient) to organize efficient education of specialist for the four disciplines CS, IS, IT, and SE in the framework of the Russian state educational standards family "Applied Mathematics and Informatics" [16]. One may deploy such an education mainly based on baccalaureate direction 010500 ("old" cipher 510200), followed (if necessary) by a specialization.

\section{Motivation to Use the Standards Family "Applied Mathematics and Informatics"}

New disciplines curricular guidelines development is undoubtedly an important task. At the same time, institutions of higher education possess much inertia and the speed of introduction and stabilization of new guidelines they can provide is considerably lower than the rate of ICT changes viewed nowadays. Under existing conditions, one of the sensible reactions aimed at accomplishing the task of infusing new curricula guidelines is the adjustment of the existing standards that are widely spread within the universities.

Flexibility is one of the important ICT curricular guidelines requirements. It allows successful use of them under diversified conditions for a rather long period. It provides flexibility by having in a standard a permanent part serving as a basis and a variable part for adjusting to the changes. To form the permanent part of the standard in Russia, it is natural to rely on Russian tradition to provide education fundamentals. The foundations of the qualification allow the production of a graduate of sound quality with a high probability of professional productivity. The authors of $[3$, section 9.1.6.] share the approach.

The role of mathematics in ICT formation and development is a fundamental one, as the ICT professional deals with formal and abstract concepts, and objects. In [3, part 9.1.1.] it stresses, "Mathematics techniques and formal mathematical reasoning are integral to most areas of computer science. $\langle\ldots\rangle$ Given the pervasive role of mathematics within computer science, the CS curriculum must include mathematical concepts early and often". Language in [4-6] expresses the same point of view.

Moreover, CS curricula models for the USA research universities include "from a one-semester course to a sequence with three or more courses" [3, part 9.4.1] of calculus. (Note that the 010500 standard provides from three up to five terms of calculus.) The list of in-depth courses [3, part 9.3.] addresses subjects as 
combinatorial analysis, probability and statistics, and many other topics, which are obligatory in the 010500 standard.

All of this allows for a sound formulation of a highly important statement that applied mathematical methods form the basis of the CS discipline. Therefore, the most important requirement to an ICT discipline curricular guideline is to form integral mathematical culture (MC) of a graduate. Possessing it, a graduate will quickly master any contemporary and coming ICT concepts, methods and technologies that are of critical importance under rapid ICT changes observed. Note also that possessing MC will enable students to master engineering ICT components quicker.

The forecast of ICT diversification process development is not clear. One of the rather likely scenarios is that due to monopolization, concentration, the applied side of ICT will reach a point of simplification, and the diversification process will begin to go in the reverse direction.

We propose, under the ambiguity conditions caused by diversification, to use the "reverse" approach to curricular guidelines formation. When we include the corresponding engineering constituents in a guideline, it will require a rather complete mathematical education. Firstly, this approach fits perfectly within the fundaments of education and accommodates the flexibility of curricular guidelines. Secondly, it provides faster reaction on diversification by adjusting existing widespread and stable university standards.

\section{Characterization of Standards Family 01050\{0|1\} - “Applied Mathematics and Informatics"}

In Russia there exists since 1993 a state educational standards family [16] "Applied Mathematics and Informatics" with education in specialty 010501 (Specialists - five years) and in the directions of 010500 (Bachelors of Science - four years, Masters of Science - six years). The bachelor standard has the following basic characteristics. The total student work content is 7,314 hours, which accounts for 132 weeks of study (eight terms). Standard courses fragment by blocks, shown as follows.

- Humanitarian and socio-economical sciences - $24 \%$

- Natural sciences - $9 \%$

- Mathematics general - $28 \%$

○ Applied mathematics - $16 \%$

- ICT general - $12 \%$

- ICT according to the faculty decision and elective courses - $11 \%$

Therefore, it is possible to provide about 1,700 hours of study of ICT within the framework of the standard; that comprises $23 \%$ of the total student work time, which programs can increase if necessary up to $30 \%$ (2,190 hours) due to the permissible standard variations.

The specialist education standard 010501 provides a total of 8,032 hours of student work content over nine terms; the tenth term is predefined for practical training and degree work development. Standard content and structure are in close agreement with the 010500 , bachelor standard; the work content is a 718-hour increase compared to 
the latter. Therefore, the fifth year of studies allows ICT study time to increase up to 2,418 hours (or $30 \%$ of the study hours).

The master training standard 010500 provides a total of 4,100 hours of undergraduate work content during 88 weeks of study for two years after completing the baccalaureate degree. Standard flexibility provides twelve different training subareas (problem fields). The ICT sub-areas are 010509 for software design, 010510 for networks software, and 010511 for system programming. The standard provides the use of $73 \%$ of the study hours for undergraduate mastering in the chosen ICT subarea. The standards family has proven itself beneficial in Russia [9]; it provides integral MC formation, sufficient time for basic ICT courses, and an elective block to reflect current ICT changes.

We now examine a question whether the 010500 bachelor standard has enough study hours to accommodate the core subjects of CS, IS, IT and SE disciplines' bodies of knowledge (BK) specified in [3-7].

\section{Comparative Temporal Characteristics of Bodies of Knowledge Cores}

We have conducted a comparative research on study hours, provided for BK cores for the IS [4, 7], the IT [5], and the SE [6] disciplines concerning CS BK Core [3]. The comparison with a description appears in Tables 1 and 2 in an extended version of this article, located at URL http://www.cs.karelia.ru/news/2006/files/sorucom-ybgven.pdf. A summary of these tables appears in Table 1.

Table 1. Summary of Discipline Comparison

\begin{tabular}{lllll}
\hline & $\begin{array}{l}\text { Hours } \\
\text { CS }\end{array}$ & IS & IT & SE \\
\hline $\begin{array}{l}\text { Total lectures in common part of } \\
\text { core }\end{array}$ & 286 & 278 & 143 & 250 \\
$\begin{array}{l}\text { Lectures in common part of core } \\
\text { (Without mathematical Subject }\end{array}$ & 243 & 235 & 100 & 207 \\
$\begin{array}{l}\text { Area Discrete Structures) } \\
\text { Lectures in special parts }\end{array}$ & N/A & 245 & 181 & 244 \\
$\begin{array}{l}\text { Lectures in core } \\
\text { Study time in special parts }\end{array}$ & 243 & 480 & 281 & 451 \\
Study time in core & None & 980 & 724 & 976 \\
& 972 & 1920 & 1124 & 1804 \\
\hline
\end{tabular}

Later on, we will use the "B standard" term for the phrase "010500 Bachelor standard". With this standard, designate as B-ICT, the study hours related to ICT study total 1,920 hours.

The temporal analysis shows that the CS core is almost entirely included in IS, SE and IT cores. Thus, we have come to the fundamental conclusion that CS core knowledge is basic for the general ICT sphere; that is, they are fundamental for the IS, IT, and SE disciplines, which implies that the latter to be applied disciplines relative to CS. This conclusion agrees well with sections of [4-6] devoted to IS, IT and SE cores connections with CS core. We also see, that the B standard, considering the 
discrete structures area as a natural introduction in its general mathematics courses block, allows accommodating the total study hours of the BK cores extend freely to each of four disciplines in B-ICT.

Finally, the temporal comparative analysis allows us to draw the following conclusions on total study hour correlation provided in B standard and in the guidelines [3-7] for CS, IS, IT and SE disciplines.

A. In [3] it states that the total CS study hours in American and Canadian universities vary greatly and it does not mention its precise extent. When computing it, assuming that besides the core the graduate is to study $12 \mathrm{CS}$ courses at 160 hours each; all in all (except for the discrete structures subject) it gives 237 lecture hours in the special part in addition to 243 core hours. That is, it contains 480 lecture hours or 1,920 study hours. It means that total CS study hours (not only BK) is entirely accommodated in B-ICT. Thus, we can think of the B standard to be a guideline [3] equivalent in both content and CS knowledge extent.

B. The total IT study hours (1,800 lecture hours) are not only entirely accommodated in B-ICT, but they allow (if using B standard for IT training) the recommended mathematical training [5, section 8.1.1] and advanced courses [5, section 8.2] for graduates.

C. The IS core extent is also accommodated in B-ICT. It appears in [4]. That is, the core extends for two years of study and the recommendations on total study hours are given in a general form as, "Prerequisite or interleaved topics directly applicable to the IS curriculum therefore include: $\langle\ldots\rangle$ discrete mathematics, introduction to calculus, introductory statistics, $<\ldots>$ principles of economics and functional areas of the organization such as accounting, finance, human resources, marketing, logistics <... ”. When using the B standard to train IS specialists, the study of mathematical courses occurs naturally, and economic and organization courses that are not in IS core, can be offered at the cost of humanitarian time block and partly in the applied mathematics block of the B standard.

D. The SE Core is accommodated entirely in B-ICT. Additional courses, recommended in [6] for the complete curriculum introduction (calculus, physics, humanitarian, and social courses) belongs also to B standard. Thus, the considerable part of total SE study hours can also be accommodated in the B standard.

The question about the possibility of accommodating the total study hours of IS and SE disciplines in B standard lies outside the scope of this article and requires additional research. At the same time it is possible to say with certainty that the specialist education standard 010501 (five years of study) allows all four disciplines graduate training in total compliance with recommendations [3-7].

Standard B adjustment for the four graduate ICT disciplines becomes a fixation of three professional blocks: the mathematical core, the ICT core, and the special blocks corresponding to each of the disciplines. 


\section{The Bachelor Direction 010500 Use Experience in Mathematical Faculty of Petrozavodsk State University}

In Petrozavodsk State University, the 010500 (510200) Bachelor direction was open in 1993 [17-19] and Master of Science direction in 1997. We developed the curriculum by taking into account the Computing Curricula 1991 recommendations. Over thirteen years, the faculty has graduated 269 Bachelors of Science students, 191 Specialists, and 73 Masters of Science students. Only a few students left the university to continue their Bachelor of Science degree at other universities. The majority of the students continued their education for one or two years to obtain Specialist or Master of Science Diploma. Graduates frequently continued their education in postgraduate school.

Our experience verifies that the B standard provides exceptional flexibility enabling one to reflect current ICT changes in the curriculum. For the last thirteen years, we have successively introduced in the curriculum studies such as introduction to processors, computer networks, operating systems, software engineering, shell language, object-oriented programming in Java and .NET environments, web technologies, and SE team project courses.

Due to the elective and facultative courses, specialized training for the system network technologies program was open in 2001 where the following courses are offered: concurrent systems, OS Unix programming, network programming, and distributed systems.

\section{Conclusion}

We have examined educational standards development and deployment problem to accomplish the task of specialist training capable of long-term efficient professional activity in the information and communication technologies sphere under its diversification and rapid considerable changes conditions. The article offers to serve the growing needs for the specialists by the adjustment of existing, widely spread standards that significantly decreases the university response time to the ICT sphere of content and demand changes.

Reasoning from the thesis that applied mathematical methods form the basis of the computer science discipline, we emphasize the importance of mathematical culture for all ICT disciplines and offer a "reverse" approach to curricular guidelines development. The gist of the approach is to introduce corresponding engineering components into a curriculum that provides intensified mathematical training. As a basic curricular guideline in Russia, it is natural to use the $01050\{0 \mid 1\}$ standard family; i.e. the "Applied Mathematics and Informatics", which is widespread in Russian universities and has been successively approved for a long time.

Accomplished temporal characteristics comparative analysis of "Computer Science", "Information Systems", "Information Technologies" and "Software Engineering" disciplines Body of Knowledge Cores shows that these Cores are entirely accommodated in the study hours of Bachelor direction 010500 provided for ICT study. 
The $01050\{0 \mid 1\}$ standard family adjustment approach to contemporary needs and ICT sphere state has the following advantages:

- Directed the integral Mathematical Culture formation;

- Approved the two stage schema for the Bachelor of Science and Master of Science programs;

- Flexible structure providing easy reaction to ICT changes;

- Adjustment process procedure simplicity compared to development, approbation, and new standards introduction processes.

The $01050\{0 \mid 1\}$ standard family uses experience in Mathematical Faculty of Petrozavodsk State University during thirteen years justifies the thesis offered in the article.

\section{References}

1. IEEE/AIS/ACM Joint Task Force on Computing Curricula. Computing Curricula 2005. The Overview Report covering undergraduate degree programs in Computer Engineering, Computer Science, Information Systems, Information Technology, Software Engineering (2005), http: / / www . computer.org/curriculum, http://www.acm.org/education/curricula.html

2. IEEE/ACM Joint Task Force on Computing Curricula. Computer Engineering 2004. Curriculum Guidelines for Undergraduate Degree Programs in Computer Engineering. IEEE Computer Society Press and ACM Press (2004),

http: / / www. computer.org/curriculum, http: / / www.acm.org/education/curricula.html

3. ACM/IEEE-Curriculum 2001 Task Force. Computing Curricula 2001, Computer Science. IEEE Computer Society Press and ACM Press (2001)

http: //www. computer.org/curriculum, http://www.acm.org/education/curricula.html

4. ACM/AIS/AITP Joint Task Force on Information Systems Curricula. IS2002 Model Curriculum and Guidelines for Undergraduate Degree Programs in Information Systems, Association for Computing Machinery, Association for Information Systems, and Association for Information Technology Professionals (2002), http: //www.acm.org/education/curricula.html, http: / / www. computer.org/curriculum

5. The ACM SIGITE Task Force on IT Curriculum. Information Technology, Computing Curricula Information Technology Volume. Curriculum Guidelines for Undergraduate Degree Programs in Information Technology, http: / /www.acm.org/education/curricula.html

6. IEEE/ACM Joint Task Force on Computing Curricula. Software Engineering 2004. Curriculum Guidelines for Undergraduate Degree Programs in Software Engineering. IEEE Computer Society Press and ACM Press (2004),

http: //www. computer.org/curriculum, http://www.acm.org/education/curricula.html

7. Detailed Body of Information Systems Knowledge, http://192.245.222.212:8009/IS2002reportsPDF/rptBodyOfKnowle dge.pdf

8. Terehov, A.N.: How to train system programmers. Computer Tools in Education (3-4), 2-80 (2001) (in Russian) 
9. Ivanovski, S.A., Liss, A.R., Romantsev, V.V., Ekalo, A.V.: Programmer's Training within the framework of State Education Standard Major and Specialization. Presentation at the 2nd conference on Information Technologies Instruction in Russia (2004) (in Russian), http: / / www.it-education.ru/2004/reports/romantsev.htm

10. Suhomlin, V.A.: IT Education: Concept, Educational Standards, Standardization Process. Hot Line - Telecom, Moscow (2005) (in Russian)

11. Nikitin, V.V.: ICT Education System Standards and Structure Development. Presentation at the 3rd Conference on Information Technologies Instruction in Russia (2005) (in Russian), http://www.it-education.ru/2005/reports/1_Nikitin.htm

12. Proceedings of First International Scientific and Practical Conference on Contemporary Information Technologies and IT Education. Moscow State University Publishing House (2005) (in Russian)

13. State Higher Education Standards: 010503 "Information Systems Software and Administration", 010300 "Mathematics, Computer Science", 010400 "Information Technologies", 080700 "Business Informatics". Ministry of Education of Russia. Moscow (2000 - 2005) (in Russian)

14. Information Technologies Instruction in Russia Conference resolution (2005) (in Russian), http: / / www.it-education.ru/2005

15. Goldweber, M., Impagliazzo, J., Clear, A.G., Davies, G., Bogoiavlenskii, I.A., Flack, H., Mayers, J.P., Rasala, R.: Historical perspectives on the computing curriculum (Report of WG no. 7). Working Group Reports and Supplemental Proceedings of ITiCSE 1997, New York, USA, pp. 94-111. ACM Press, Uppsala (1997)

16. State Higher Education Standard. 010500, Applied Mathematics and Computer Science. Degree - Bachelor of Applied Mathematics and Computer Science, 010501 - Applied Mathematics and Computer Science. Qualification - Mathematician, system programmer, 010500, Applied Mathematics and Computer Science. Degree - Master of Applied Mathematics and Computer Science, Ministry of Education of Russia, Moscow (2000) (in Russian)

17. Voronin, A.V., Bogoiavlenskii, Y.A., Kuznetsov, V.A., Poljakov, V.V., Sigovtsev, G.S.: E02 "Applied Mathematics and Computer Science" Baccalaureate Education Program. In: All Russian Guidance Conference "Teachig strategy bases of Multilevel Education System Development and Functioning" abstracts (in Russian)

18. Pechnikov, A.A., Bogoiavlenskii, Y.A., Voronin, A.V., Kuznetsov, V.A., Poljakov, V.V., Sigovtsev, G.S.: E02 "Applied Mathematics and Computer Science" PetrSU Baccalaureate Program. Applied Mathematics and Computer Science, vol. 3, pp. 75-80. Petrozavodsk State University Publishing House (1994) (in Russian)

19. Bogoiavlenskii, I., Pechnikov, A., Sigovtsev, G., Voronin, A.: Using of Computing Curricula 1991 for Transition from "Mathematics" to "Applied Mathematics and Computer Science" Baccalaureate Program. In: Abstracts of Conference ITiCSE 1997, p. 8. University of Uppsala, Uppsala (1997) 